\title{
Surface Composite Fabrication by Friction Stir Processing: A Review
}

\author{
Anubhav Sharma ${ }_{1}^{1^{*}}$ Sachin Maheshwari ${ }^{1}$ and Pradeep Khanna ${ }^{1}$ \\ ${ }^{1}$ Department of Mechanical Engineering, NSUT, New Delhi , India.
}

\begin{abstract}
Newer materials with unique properties are needed to cater the ever-increasing industrial demands to meet new challenges concerning technological advancements. Quest for special materials and processes is prevalent as conventional materials fail to level up. Composite materials promisingly bridge this gap by providing controllable properties at reasonable costs. Their scope of application can further be drastically enhanced by subjecting them to special surface processing treatments. Friction stir processing (FSP) is one such promising process that can meet the stringent applicational demands. Composites are increasingly being used in industries for properties like high strength to weight ratio, increased hardness, stiffness, ductility, corrosion resistance, etc. FSP, a solid-state material modification technique, has proved its caliber in surface composite fabrication. Some attention-seeking advantages of FSP include peerless efficiency, less tool wear rate, and ability to modify material locally are some of many attention-seeking advantages. Despite being cost-effective FSP also manages to eliminate the drawbacks of the conventional manufacturing process. FSP reinforces a special material into the parent material surface to attain specific properties. Properties so developed depend on parameters like: tool geometry, traverse speed, rotation speed, number of passes etc. The present paper aims to review comprehensive information on fabrication of surface composites by FSP, process parameters, properties, industrial applications, and future scope.
\end{abstract}

Key Words: Friction stir processing, surface processing treatments, surface composites, material modification, process parameters.

\subsection{Introduction}

Composites are a heterogeneous combination of two or more chemically and structurally different components. The combination has properties that are not exhibited by the components individually in isolation. One of the simplest advantages of composites over alloys is high strength to weight ratio. Surface composites are modified material with properties of composite layer at the surface while the bulk material retains it's base properties [1]. Surface composites have their application in automotive, aerospace, biomedical, textile etc [2].Various techniques for fabrication of surface composites are there and one novel technique grabbing the attention is Friction stir processing (FSP).

Friction Stir Processing is developed on the principle of Friction Stir Welding (FSW). It is a environment friendly processing route for the fabrication of surface composites. It has gained advantage over other liquid phase processing techniques in terms of energy efficiency. The process is carried out at much lower temperature than the melting point of the base material. No melting of the material during processing in FSP helps avoid defects like thermal cracks and porosity which are prominent issues in liquid state processing techniques [3].

FSP has its applications in diverse fields like marine, aerospace, automobile, biomedical, railways etc. As per recent research FSP fabricated composites can readily be used in nuclear fuel applications over conventionally processed composites [4-6]. The base metal (matrix) is processed using a non-consumable tool with a rotating shoulder and pin (probe). As the tool rotates the pin plunges inside the matrix while the shoulder stays in contact with the surface of the matrix. The heat generated due to friction between the shoulder and the matrix causes the material to turn semi solid [7]. This direction of the work piece with the semi-solid material flowing is called the advancing side. While the other end of the work piece which received the cooled material is called the retreating side [8]. The whole process is depicted in figure 1(a). Processed regions generated after FSP are: stir zone (SZ), thermomechanically affected zone(TMAZ) and heat affected zone (HAZ) [9]. These zones are shown in figure 1(b). The entire process is a thermo-mechanical process. The semisolid material undergoes severe plastic deformation (SPD) leading to dynamic recrystallization (DRX) and therefore reduction in grain size[10]. The tool probe is responsible for stirring the semisolid material in the zone called the stir 
zone (SZ).This zone experiences the maximum heat and hence highest SPD followed by DRX [11]. The grains in this zone are continuously forced to undergo deformation and hence produce equiaxed grains with high angle grain boundaries (HAGB's). While the processed zone also undergoes deformation and has an increment in the number of HAGB's [12]. The angle of dislocation in HAGB's is more which promotes slippage and therefore increases the plasticity of the material [13]. Concentric rings can be seen as a result of the tool rotation leading to the flow of the material, an area which underwent plasticization and grain refinement [14]. TMAZ being subjected to thermal cycling, experiences grain refinement and partial recrystallization. In this zone the precipitate phase is observed to be disintegrated [15].Micro-structural, mechanical and tribological properties of the material are affected during the process. As per Hall-Petch strengthening, the decrease in the grain size results in increase in yield strength therefore the strength of the material increases with the decrease in the grain size [16].Both micro-structure and mechanical properties are seen dependent on each other from this.

\subsection{Surface composites by FSP}

Surface composites have a parent material and a second phase called the reinforcement material. Reinforcement material plays a crucial role in imparting the surface composite with peculiar properties, depending on its own basic properties. When the second phase particles are distributed uniformly they show a pinning effect to hold the boundaries and do not let the re-crystallization to happen [17].

FSP has an upper edge over other techniques as there is no or little inter-facial reaction between the participant materials [20]. Moreover in this technique we have greater control over processing parameters which makes it easier to obtain desired properties. Now fabrication of surface composite by FSP also has quite a few options to choose from: like using groove method or drilled hole etc. In the groove method a groove is made throughout the plate and filled with reinforcement. This filled groove is then sealed with a tool that has no pin and later the tool with pin carries out the main process [21]. This sealing eliminates the scattering of reinforcement. On the other hand in the drilled hole method holes are drilled of a certain dimension in the base plate.After filing these holes the tool is made to move through plate making a layer of surface composite in the plate. While reinforcing copper with $\mathrm{SiC}$ two arrays of drilled holes were made which helped reduce agglomeration of the reinforcement material.Use of holes helped in uniform distribution of $\mathrm{SiC}$ particles in the stir zone. To avoid the ejection of the reinforcement particle a thin sheet was used to cover the drilled holes [22]. Figure 2 shows the groove and drilled hole method.

Studies have used consumable tools as well that have pre filled reinforcement in tool that gets displaced in the matrix plate while processing. Fabrication of the composite layer of Al-SiC by friction stir surfacing was successfully done in a study. Blind drilled holes were used to pack the reinforcing particles in a $20 \mathrm{~mm}$ diameter rod of AA6082T6. Friction stir surfacing of AA2024-T3 alloy was done using this particle packed rod. As the temperature rises the tool consumption increases causing these layers to exhibit variable thickness.
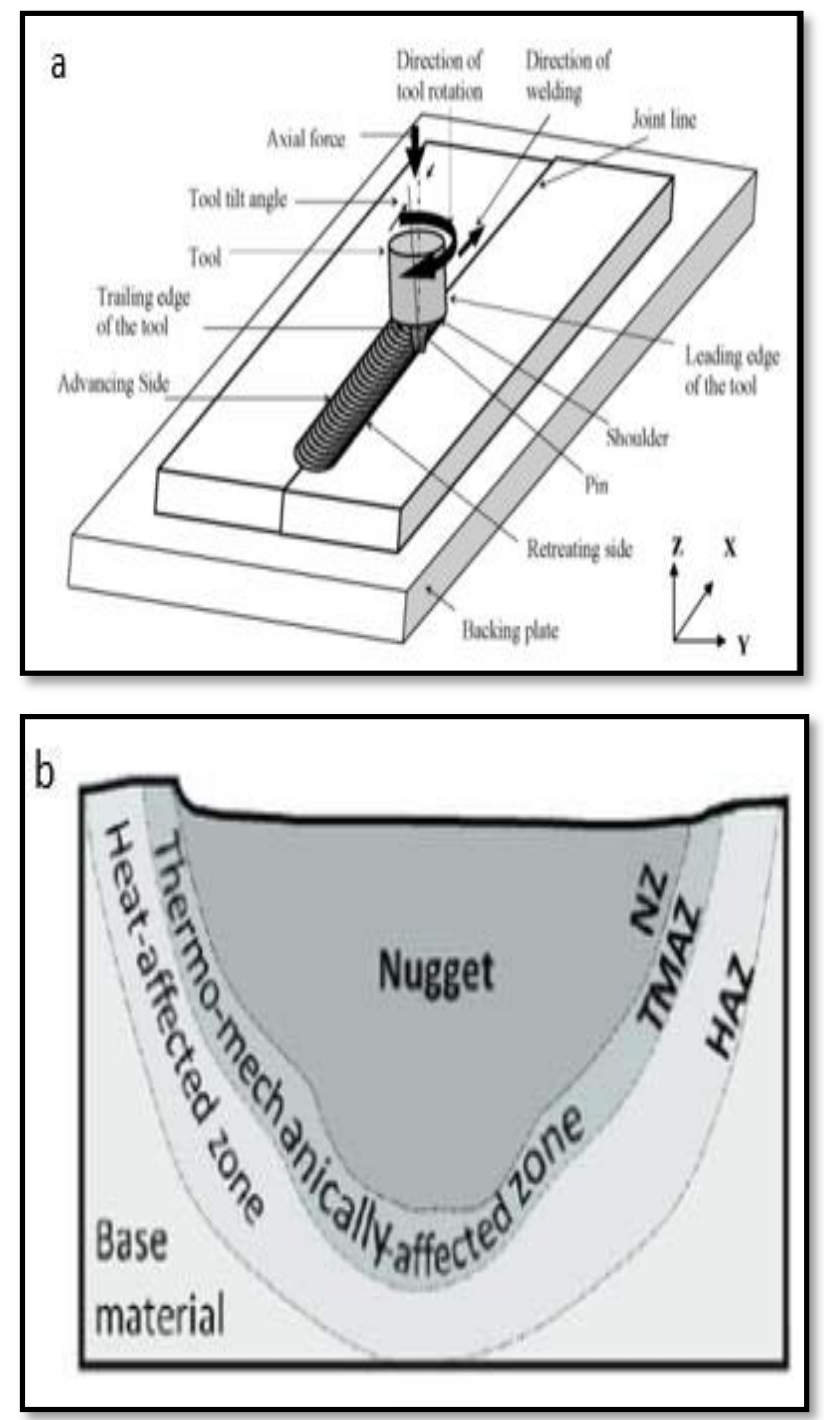

Fig 1: Schematic representation of (a) Friction Stir Processing (FSP) [18], (b) Processed zone after FSP [19] 


\begin{tabular}{|c|c|c|c|}
\hline Matrix Metal & Reinforcement & $\begin{array}{l}\text { Method used } \\
\text { for } \\
\text { reinforcement } \\
\text { addition } \\
\end{array}$ & Concluding Remarks \\
\hline AA5083 & $\mathrm{SiC}$ & Smearing & Micro-hardness for the material AA5083 doubled. \\
\hline Ti-6AI-4V & $\mathrm{B}_{4} \mathrm{C}$ & Holes & $\begin{array}{l}\text { Reinforced material has enhanced wear resistance than mild } \\
\text { steel and stainless steel. }\end{array}$ \\
\hline $\mathrm{Cu}$ & $\mathrm{B}_{4} \mathrm{C}$ & Groove & $\begin{array}{l}\text { As the volume fraction for } \mathrm{B}_{4} \mathrm{C} \text { increased the micro hardness } \\
\text { and wear resistance was also found increasing. }\end{array}$ \\
\hline AA5083 & $\mathrm{CeO}_{2}+\mathrm{CNTs}$ & Groove & $\begin{array}{l}\text { Increasing Volume fraction of CNT's helped increase tensile } \\
\text { strength. }\end{array}$ \\
\hline Al-Mg & $\mathrm{TiO} 2$ & Groove & $\begin{array}{l}\text { Grain refinement was observed with significant change under } \\
\text { cryogenic condition. }\end{array}$ \\
\hline A356 & $\mathrm{B} 4_{\mathrm{C}}+\mathrm{MoS}_{2}$ & Holes & Hardness and wear resistance increased. \\
\hline A356 & $\mathrm{Al}_{3} \mathrm{Ti}$ & Casting & $\begin{array}{l}\text { Multi pass FSP enhanced strength as well as ductility of the } \\
\text { material. }\end{array}$ \\
\hline $\mathrm{Mg}$ & HA & Groove & $\begin{array}{l}\text { Increase in the hydroxyapatite particles decreased the Corrosion } \\
\text { resistance }\end{array}$ \\
\hline AZ91 & $\mathrm{Al}_{2} \mathrm{O}_{3}$ & Groove & $\begin{array}{l}\text { Increased hardness along with wear resistance was seen } \\
\text { increasing. Also grain size reduction was observed for which } \\
\text { nano } \mathrm{Al}_{2} \mathrm{O}_{3} \text { was responsible. }\end{array}$ \\
\hline Al1050- H24 & $\mathrm{Fe} / \mathrm{Fe}_{3} \mathrm{O}_{4}$ & Groove & $\begin{array}{l}\text { AA1050/Fe had higher saturation magnetization as compared } \\
\text { to that of the } \mathrm{AA} 1050 / \mathrm{Fe}_{3} \mathrm{O}_{4} \text {. }\end{array}$ \\
\hline Al-Mg & GNPs & Groove & $\begin{array}{l}\text { Major strengthening mechanism here was CTE (coefficient of } \\
\text { thermal expansion) }\end{array}$ \\
\hline Al-Mg & $\mathrm{SiC}$ & Groove & $\begin{array}{l}\text { Strengthening mechanism responsible was grain boundary } \\
\text { mechanism. }\end{array}$ \\
\hline AZ31 & CNTs & Groove & $\begin{array}{l}\text { Performing } 2 \text { passes of FSP ensured homogeneous distribution } \\
\text { of the CNTs. }\end{array}$ \\
\hline AA2024 & $\mathrm{Al}_{2} \mathrm{O}_{3}$ & Groove & $\begin{array}{l}\text { Number of FSP passes controlled the quality of surface } \\
\text { composites. }\end{array}$ \\
\hline A11050- H24 & GNSs & Groove & $\begin{array}{l}\text { Friction coefficient was reduced where graphene particles } \\
\text { served as lubricant. }\end{array}$ \\
\hline AA6061- T6 & $\mathrm{Al}_{2} \mathrm{O}_{3} / \mathrm{SiC}$ & Groove & $\begin{array}{l}\text { Increasing reinforcement volume percentage increased the wear } \\
\text { resistance of nano- composite surface }\end{array}$ \\
\hline AA2024 & $\mathrm{Al}_{2} \mathrm{O}_{3}$ & cold spraying & $\begin{array}{l}\text { Bonding between in improved particle and dispersion } \\
\text { strengthening of the } \mathrm{Al}_{2} \mathrm{O}_{3} \text { particles were found responsible for } \\
\text { strengthening mechanisms. }\end{array}$ \\
\hline Ti-6AI-4V & $\mathrm{Zn}$ & Holes & $\begin{array}{l}\text { Enhanced mechanical and biocompatible properties were } \\
\text { developed on the surface nano composite. }\end{array}$ \\
\hline $\mathrm{Al}$ & $\mathrm{AISi}_{10} \mathrm{Mg}$ & $\begin{array}{l}\text { Selective laser } \\
\text { melting }\end{array}$ & $\begin{array}{l}\text { Micro structure and reduction in porosity can be achieved with } \\
\text { FSP. }\end{array}$ \\
\hline
\end{tabular}

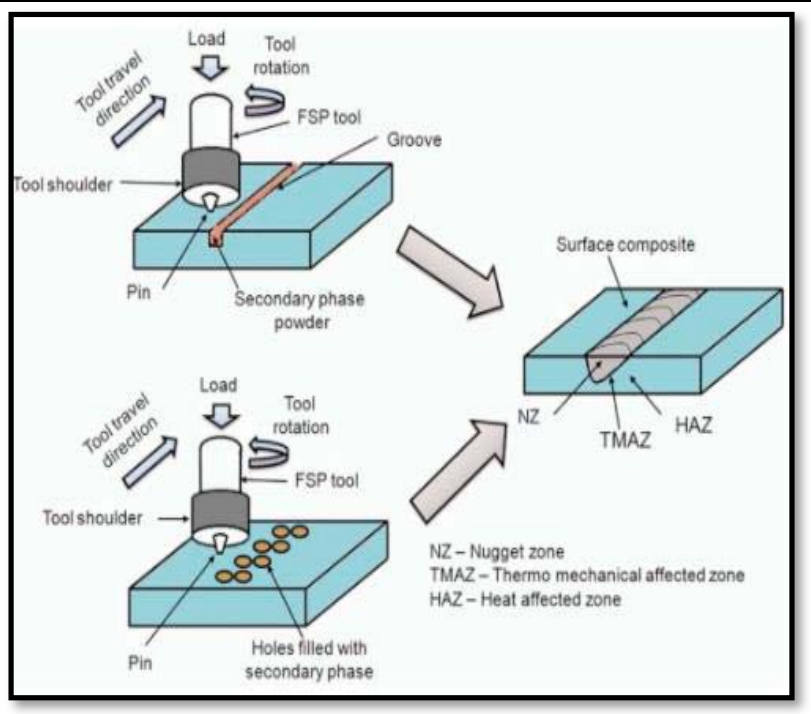

Fig 2: Groove \& drilled hole method [23].
Table 1: Some successful Surface composites made by FSP

Although due to non-occurrence of tool wear there were no defects and the reinforced layers were found free from inclusions [24]. Also, covering the base metal with layer of reinforcement and consecutively carrying out FSP is another method.

This enables wider distribution of reinforcement particles. On a AA2024 alloy plate $200 \mathrm{~mm}$ thick coating of Al-10\% nano-sized $\mathrm{Al}_{2} \mathrm{O}_{3}$ was deposited by air plasma spraying method. Nano surface composite was fabricated 
particle layer was cold sprayed on the on the base plate. The reinforcement was $\mathrm{Al}-\mathrm{Al}_{2} \mathrm{O}_{3}$ and base metal was AA6061. Volume Fraction of $\mathrm{Al}_{2} \mathrm{O}_{3}$ was obtained to be as high as $48 \%$ and hardness was increased from $85 \mathrm{Hv}$ to 137 Hv after FSP [26]. Table 1 shows some surface composites

\subsection{Review of Literature}

Second phase particles and efficacious grain refinement characterizes FSP. Additionally,mechanical properties are improved further in high strength alloys due to phase transformation by FSP [28]. Energy efficiency, environment friendly and versatility of FSP has successfully been proved by the modification brought in the micro-structural and mechanical properties of the material by reducing the grain size, hardness, ductility etc and synthesizing in-situ composite/inter-metallic compound. FSP can be developed to produce localized modifications with controlled micro-structural properties [29].

Techniques like plasma spraying and laser cladding are used for fabrication of the composites and improve their surface properties. Hot cracking, porosity and other such defects are found to be there while working with all these methods as they involve melting of material. By FSP, for fabrication of surface composites a uniform distribution of strengthening phase can be obtained. Also burning of reinforcing particles and formation of harmful phases, that happens at high temperatures involved with the conventional methods is absent in FSP. Different kinds of second phase particles generally added while performing FSP process include GNPs, CNTs, $\mathrm{SiC}, \mathrm{B}_{4} \mathrm{C}$ and $\mathrm{Al}_{2} \mathrm{O}_{3}$, etc. [27]. Magnesium based hybrid composites fabricated by FSP not only increases the micro-hardness of the surface but also the wear resistance enhances as compared to stir cast composite samples [31]. Microstructural features were displayed slight grain structure refinement after FSP of Al-Mg alloy due to the DDRX mechanism.

While formation of the in-situ inter-metallic composites the introduction of the reinforcement material was done, reduced grain size was found to be reduced to nano scale operating on PSN and Zener-pinning mechanisms during DRX. The high strength of in situ Al$\mathrm{Mg}-\mathrm{Al}_{3} \mathrm{Ti}$ nano composite prepared by FSP can be attributed to the presence of $\mathrm{Al}_{3} \mathrm{Ti}$ nano particles and introduction of more reinforcing particles. These nano particles contribute in the strength of the material through the Orowan mechanism. Fractographic studies revealed a combined ductile-brittle rupture manner depending on the role of metallic/inter-metallic phases with respect to completely ductile failure behavior of initial annealed Al$\mathrm{Mg}$ alloy and FSPed Al-Mg alloy without reinforcing particles [32].

The ratio of tool rotation and tool traverse speed and number of passes should in such a way that it generates enough heat to promote the reaction but not too much that will melt the material causing coarse micro structure and large cavities in SZ. Contact area of the interface by with their reinforcement and matrix material, fabricated by FSP.

shearing metal powders and by detaching the intermetallic layer surrounding the constituent element can be significantly enhanced with increase in the number of passes. Particle dispersion is influenced by tool geometry up to a great extent [34]. The base material, volume of processed material rate of heat generation and reinforcement mixing condition are the factors on which traverse force depends on. Traverse force is most influenced by tool rotation speed followed by traverse speed and shoulder diameter. Somehow, tool rpm is found not to affect traverse force. Traverse force increases with the increases in the traverse speed increases for higher processing rate the material is relatively cooler and hard The traverse force increases with increase in tool shoulder diameter due to the increase in drag force which was attributed to large shoulder diameter [36].

The micro-structural investigations revealed fine and uniform distribution of reinforcement when drilled holes method was used. There is a tendency of particles to agglomerate had decreased resulting in further enhancement of mechanical properties [35]. The mechanical, tribological and corrosion resistance properties enhances when the number of passes is increased. Carrying out FSP up to four passes modifies the micro-structure properly, causing the enhancement of properties accordingly [37].

Bio compatible AZ31-nHA composites were successfully fabricated by FSP. The processed surface had fine grain structure which resulted in improved wettability [38]. As compared to AZ31 magnesium metal matric composite and even FSPed AZ31, this newly fabricated AZ31-nHA composite had excellent bio-miniralization and corrosion resistance. Cell adhesion was found to be promising in these fabricated composites.

\subsection{Effect of process variables}

Process variables can be broadly classified into following three categories: (1)Machine variables (2)Tool design variables (3) Material properties. These are concisely mentioned in figure 4. 


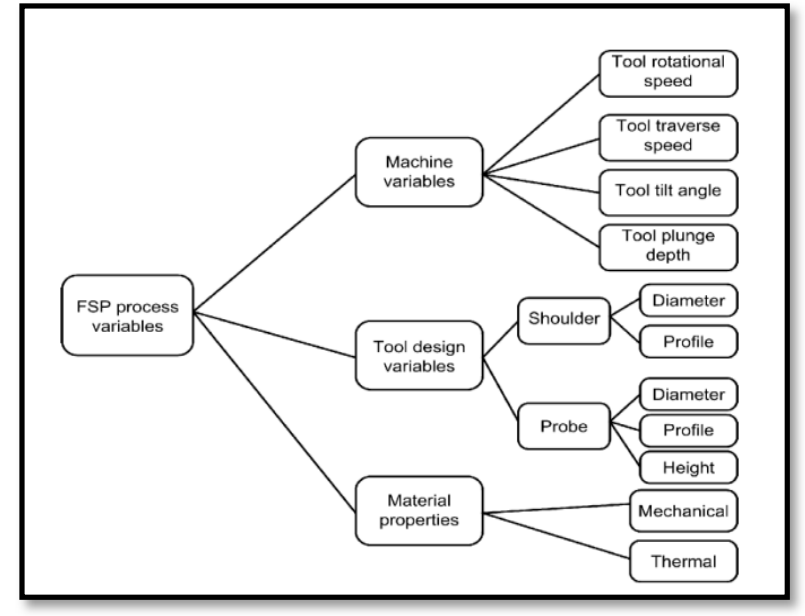

Fig 4: Various variables of Friction Stir Processing technique [39].

The baseline for the selecting the process parameters is the type of material being used and it's mechanical and thermal properties. In materials with high melting point, high heat input is required [40]. The heat involved in the process plays a major role and this heat depending on the amount affects the materials differently based on the thermal properties of that material.During FSP plastic deformation is controlled majorly by hardness,yield strength (YS) and ductility of base the material

\subsection{Machine Variables}

Two major parameters during the process of FSP are : tool rotation speed and traverse speed of the tool that come under the category of machine variables. These speeds directly affect the heat generated in the process and material flow[30]. Moreover the inter-facial reaction between phases also depends on these speeds.Both of these play a crucial role in imparting different mechanical and micro-structural properties to the composite. More grain refinement is achieved if the heat generated is less and the opposite happens if the heat generated is more. Heat generated must be of appropriate amount to soften the material for the tool pin to stir components in the stir zone. In contrast a very high rotation speed makes and impact on the grain refinement due to increased input of heat [42]. An optimized rotation speed helps in the proper distribution and de-clustering of the reinforcement particles. Traverse speed of 20,30 and $63 \mathrm{~mm}$ per minute was used for the fabrication of $\mathrm{SiO}_{2} / \mathrm{AZ} 91$ which resulted in the grain refinement in the stir zone with increased hardness. Very high traverse speed was reported to affect the bond between the base material i.e. Aluminum alloy and the composite layer. The bonds were found to be weak with lower rotation speed; low heat exposure due to lower rotation speed and low traverse speed gives lesser time for heat exposure and vice versa [43]. The results showing effect of traverse speed are shown in table 2.

As for in-situ fabrication of $\mathrm{Al}-\mathrm{TiO}_{2}$ it was noticed that the traverse speed played a more significant role than rotation speed. The reaction between the selected reinforcement and the base material occurred when the traverse speed was reduced. Reduction in the traverse speed increased the stirring duration and also helped increase the temperature which in-turn helped in the diffusion of the materials [44]. Clustering of $\mathrm{SiC}$ was reduced by increasing both the rotational and traverse speed in proportion while processing SiC/AZ31 [45].

Table 2: Effect of traverse speed on the grain size and micro-harness in SZ.

\begin{tabular}{|l|l|l|}
\hline $\begin{array}{l}\text { Traverse } \\
\text { Speed } \\
\text { (mm/min) }\end{array}$ & $\begin{array}{l}\text { Grain size } \\
\text { (microns) }\end{array}$ & $\begin{array}{l}\text { Micro } \\
\text { Hardness(Hv) }\end{array}$ \\
\hline 20 & 14.12 & 85 \\
\hline 40 & 11.07 & 99 \\
\hline 63 & 8.27 & 108 \\
\hline
\end{tabular}

\subsection{Effect of Tool Geometry}

The tool geometry plays and important role in the fabrication process as it plays vital role in the generation of heat and flow of material, eventually leading to the micro-structural properties. Tool geometry includes the shoulder diameter, probe diameter and its length. Diameter of the shoulder controls the heat generated which in turn controls the processing of the material. Smaller shoulder diameter fails to generate sufficient heat for the material to flow therefore creating defects in the processing [46]. Among the different tool probe shapes in use are depicted in the figure 5 :

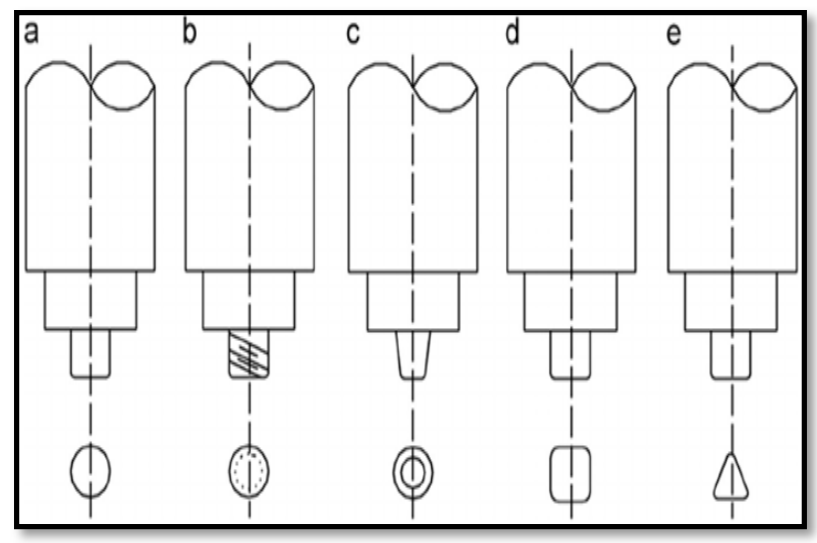

Fig 5: Various tool pin profiles. (a) Straight Cylinder (b) Threaded Cylindrical (c) Tapered Cylindrical (d)Square and (e) Triangular [47].

As stated above there are several tool shapes, geometry available which influence the micro-structures and mechanical properties of the composite material. The tool shoulder friction with the matrix generates heat which plasticizes the material and therefore enables the processing [48]. The larger the diameter of the shoulder more heat would be generated for the material to plasticize more. Generally the shoulders are concave shaped acting as hood for the deforming material.Also the tilt angle plays a role in providing space for the material to move in. Fabrication of Aluminum alloy with $\mathrm{SiC}$ with 3 types of tool shapes: square, cylindrical and triangular was done and investigated. It was noticed the use of square shaped 
tools helped more uniform distribution of $\mathrm{SiC}$ particles. There was also observed formation of minute Iron aluminides due to the deterioration of sharp edges of triangular and square tools, called the tool wear. Cylindrical tool underwent less tool wear [49].

In a study the material flow and transfer of heat was investigated. This study focused on evaluating a threaded and a non - threaded pin while conducting FSP. It was evaluated that the threaded pin immensely affected the velocity of the material flow, rate of strain around the Stir Zone as well as heat distribution [50].

\subsection{Effects of Number of Passes:}

Tool pin diameter decides the width of the processed zone, nearly $8 \mathrm{~mm}$ diameter pin generates a processed zone of 10-14 mm diameter. Such processed materials do not carry a great commercial value. Therefore to combat the problem the processing is done more than one time which is called the multi pass in technical terms.Carrying out multiple passes has a major effect on the homogeneity of the reinforced phase [51]. The even distribution of secondary phase particles plays an influential role in mechanical as well as micro-structural properties of processed material. The strength of surface composite fabricated gets adversely affected by the clustering or uniform distribution. Number of passes not only affects the distribution of reinforcement but also enhances the properties like grain refinement, hardness, strength etc. of the matrix as well. It adds up to the decrease in grain size of the matrix [52]. Figure 6 shows a schematic representation of surface modification by multi pass FSP.

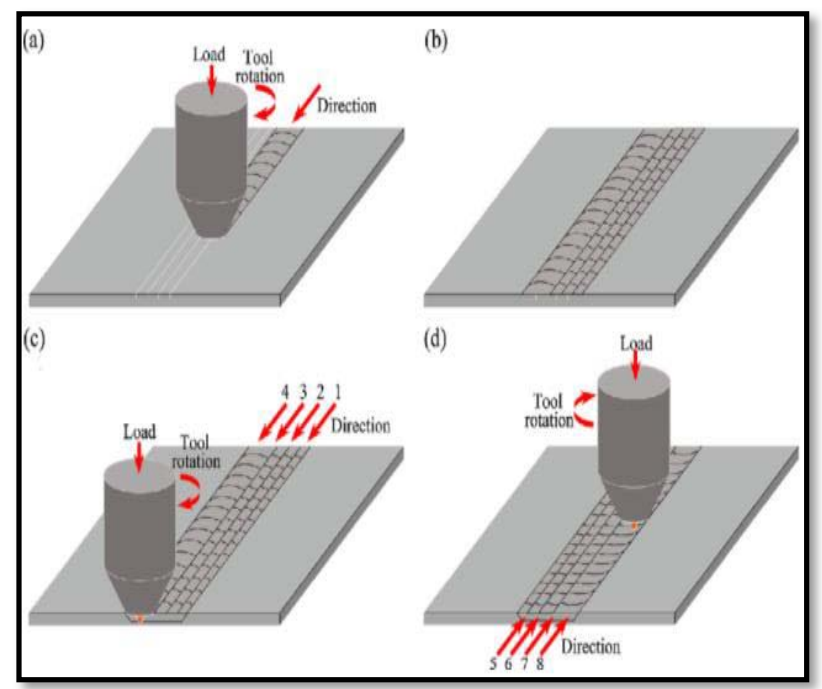

Fig 6: Multipass FSP (a) pin less tool sealing process, (b) sealed magnesium alloy surface, (c) FSPed with pin tool of 1 pass, (d) FSPed with pin tool of 2 pass [53].

Uniformly distant overlapping was done 5 to 6 times which helped reduce the dendritic micro-structures in the alloys A319 and A356. Multi pass FSP helped increase the ultimate tensile strength, fatigue life and the hardness in both the processed alloys. Figure 7: shows the optical image of processed alloy A319, (a) shows the marginal area of the stir zone while (b) shows the middle of the Stir zone with the uniformly distributed particles after multipass FSP.

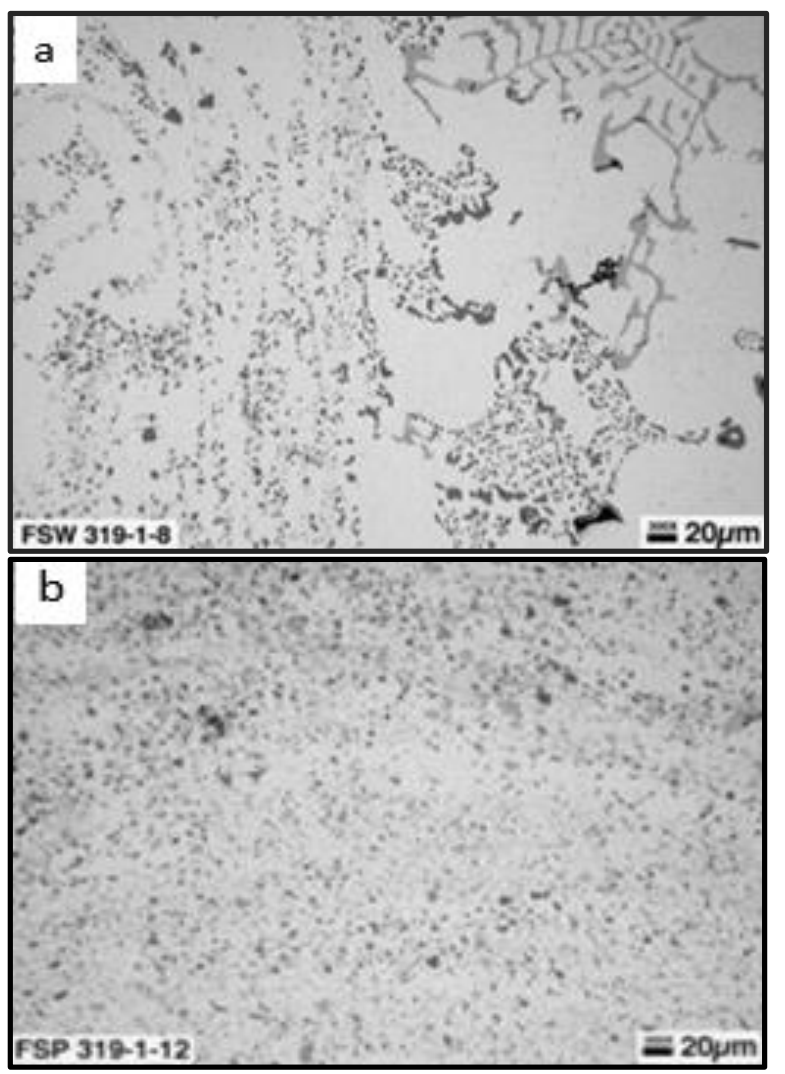

Fig 7: Optical microscopy of A319 alloy Stir zone after Multi pass FSP [L (a) to R(b)] [54]

Five overlapping passes were performed on AA6061 alloy, equiaxed grains of 3.9 micrometer were produced in overlapping stir regions, this helped increase the ductility while due to thermal softening the strength of the processed material dropped below the actual material. Five passes increased the corrosion resistance in the material due to homogenization of the fine grains [55]. Uniform distribution of Si particles was observed in the processed zone. Ductility and Strength increased with the increase in number of passes.In-situ fabrication of $\mathrm{SiC}$ particles on Copper metal was done with increasing number of passes which resulted in the increase in the ultimate tensile strength, reason for which was concluded as reduction in the porosity and the increased association of metal matrix and the $\mathrm{SiC}$ particles. The results showed that, the micro hardness increased by $30 \%$ on 1 st pass, $50 \%$ on 4 passes and by $58 \%$ with 8 passes, this similar demonstration is seen in the graph in figure 8 : 


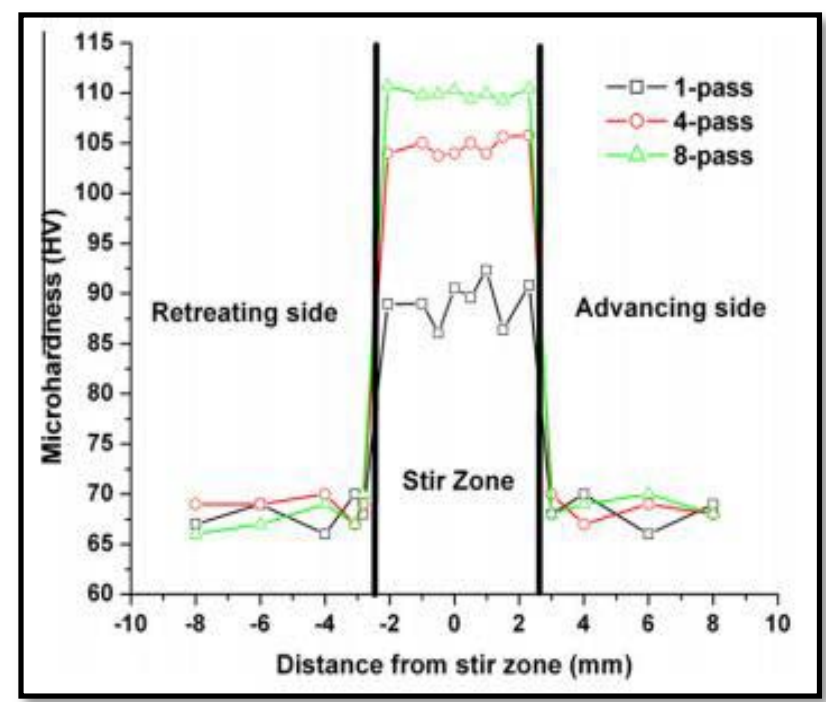

Fig 8: Micro-hardness of copper after multipasses of FSP[56].

The graphs in figure 9 shows the effect of number of passes on $\mathrm{AZ} 91 / \mathrm{SiO}_{2}$. The hardness in $\mathrm{SZ}$ increases with number of passes. The homogeneity of distribution of particles also enhances the grain size decreases and thus increase in hardness. The Stress Strain curve for same specimen is been depicted, which clearly shows increase in elongation with increasing number of passes in reference to the stress. Micro-hardness and Elongation properties of the composite processed with tool rotation speed $1250 \mathrm{rpm}$ and traverse speed at $63 \mathrm{~mm} / \mathrm{min}$ with increasing number of passes.

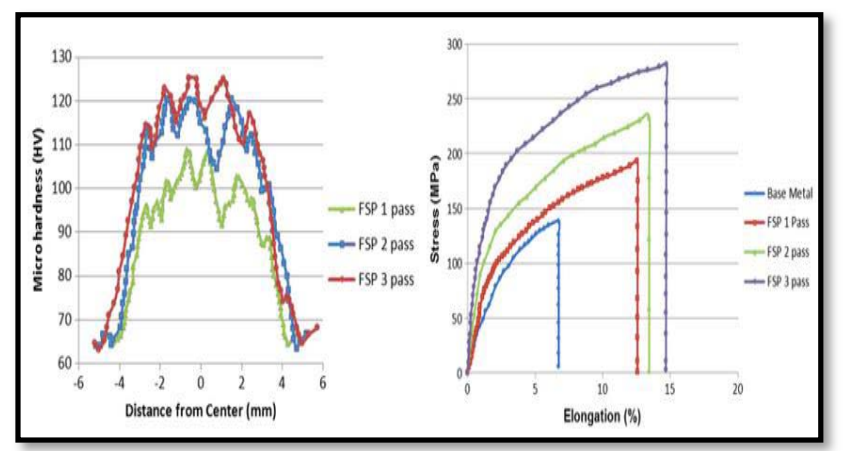

Fig 9: Micro-hardness, stress and elongation variation with number of passes [47].

\subsection{Effect of Reinforcement}

Numerous studies give the reference of how the type, shape and size of the reinforcement plays a vital role in the properties exhibited by the surface composites. Three major ways by which the reinforcement can be incorporated in the matrix are:

1. As Grainy/ Particulate material

2. As Individual Fibers

3. As Fiber sheets /Layers

The reinforcement plays a role in providing strength, stiffness, and improves thermal expansion along with conductivity. Type of reinforcement and volume fraction of the reinforcement plays a role in the development of the properties in the composite. It is proposed that fiber reinforcement increases the strength more than the particle reinforcement [57]. As per the studies, reinforcement with continuous fibers increases the mechanical properties as compared to the short fibers, explaining the importance of physical attributes of reinforcement phase contributing to composite properties.Fiber composites are generally reinforced either on plastic or on metal with maximum volume of fraction reaching upto $70 \%$. Such composites have high young's modulus and high stiffness. Changing the reinforcement material too plays a role in changing the properties, for instance use of aramid fibers instead of glass fibers reduced the weight of the composite by $30 \%$ also increasing the economic efficiency. Reinforcement of para-aramid fibers are analyzed to enhance strength, tensile fatigue property along with giving specific stiffness to the composite. Such composites have low inter laminar shear strength and cause difficulty in the cutting process [58]. Aramid fibers are actively used in making helicopters and other commercial aircrafts.

Moreover the reinforced material greatly affects the movement of grain boundaries during the process. The volume fraction of reinforcement particles does play a role in grain refinement as well. In-fact studies have resulted in reduction in grain size of matrix due to the reinforcement particles. A decrease in grain size of AZ31 alloy was seen when reinforced with $\mathrm{SiC}$ particles. The grain size with reinforcement was about 2 micrometers whereas without reinforcement it was 5 micrometers [59]. The secondary phase particles restrict the abnormal grain growth and hence the reduced grain size and refined micro-structure.

\subsection{Defects during FSP :}

FSP, being cost effective and a novel technique in comparison with the conventional ways of fabricating composites. Overlooking these merits there are defects observed in composites made using FSP. Defects occurin FSP are similar to ones seen in FSW, for instance: surface galling, nugget collapse, surface lack fill, wormhole, ribbon flash etc. Major reasons for defects in friction stir processed composite can be abnormal heating.

\subsection{Flash defect:}

Due to high tool rotation speed excessive heat is generated, the speed of the tool rotation is higher than the traverse speed. The heat causes the material to flow and severe plastic deformation to begin [60]. The heat generated is so much that it causes excessive softening of the material.Alongside this the pressure of the tool shoulder causes the material to flow from the edge in the form of flash [61]. The pictorial representation of flash defect is shown in figure $10(\mathrm{~b})$.

\subsection{Void defect:}

Insufficient heat input due to high traverse speed and low rotation speed causes formation of a void on the advancing side. High traverse speed also leads to the formation of worm hole defect due to lack of filling and insufficient 
plastic flow [62]. Cavity and void defects are also developed due to insufficient stirring, causing the temperature difference in the top and the bottom surface, leading to discontinuous flow of the material [63]. High rotation speed and traverse speed are also responsible for this defect. These defects can be easily seen with the help of figure 11 giving an insight of role of traverse speed and rotation speed in development of defects [64]. Figure 10(E) shows void defect.

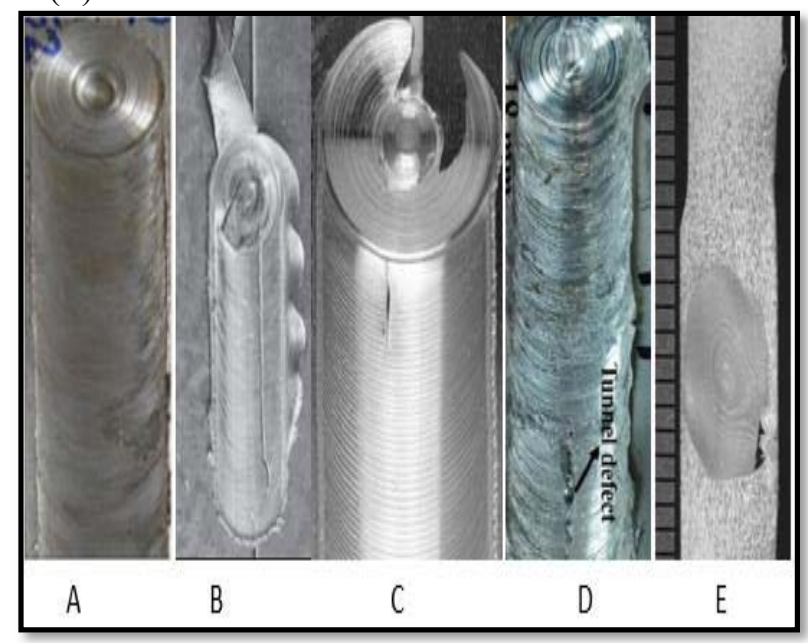

Figure 10: Defects seen after Friction Stir Processing, (A) Normal Processed sample (B) Flash defect (C) End hole defect (D) Tunnel defect (E) Cavity defect [61-64].

Sources of defects can be selection of parameters including: tool rotation speed, traverse speed, shape of the tool pin, tool pin plunge depth etc. [65]. Excess input of the heat, a flash is observed on the retreating end, while insufficient heat generation leads to generation of a hole on the composite surface and a prominent cavity due to improper stirring in the stir zone [66]. Here the tool shoulder and tool pin may evidently be responsible for generating these defects. In $\mathrm{SiC} / \mathrm{AA} 5083$ cavities in triangular shape were observed, along with agglomeration of particles. Two cavities were observed: Advancing side had the empty cavities while the retreating side had particle filled cavities due to force exerted by the material flow [67]. Tool traverse speed and tool rotation speed are known to cause heat generation followed by material flow and plastic deformation. Their balanced ratio between the two helps decide the time duration for which the tool pin and tool shoulder stay in contact with the material under processing. If the ratio of the two parameters is very low, tunneling defect is observed. While reinforcing Silicon Carbide on Titanium to prepare a nano-composite tunnels and voids were observed in the stir zone with low ratio of traverse and rotational speed,similar such defected were reported with $\mathrm{Al}_{2} \mathrm{O}_{3} / \mathrm{AA} 5052$ [68]. Three fluted and nonthreaded tools, led to minute voids and cavities due to less flow in the material [61]. Indicating the role of tool geometry in avoiding the defects. Pictorial representation of various defects is shown in Figure 10.

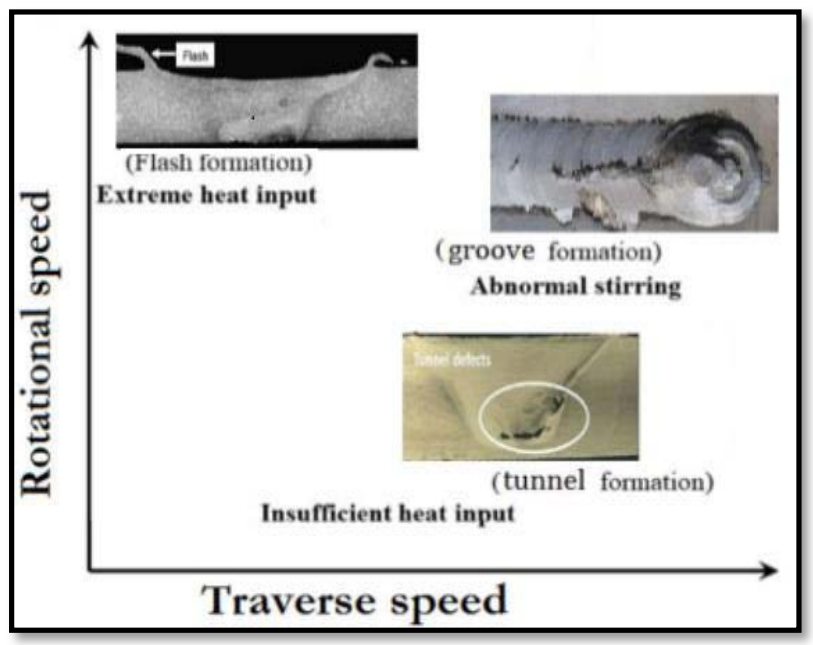

Figure 11: Defects due to variation in tool rotation speed and traverse speed [61].

\subsection{Applications of Surface Composites fabricated by FSP}

As the composites have found their use in almost every field in this day and age, hence the FSP also have become adaptable in diverse industries to fabricate the surface composites. Some major industries that cover a broad spectrum are aerospace, automotive, biomedical, nuclear and petrochemicals. Certain applications require enhanced surface properties like wear resistance for the efficient life of components, for these situations surface composites having surface layer reinforced by particles of desired properties while original properties are retained at bulk [69]. The materials are required to have properties such as specific strength, stiffness, light weight, fatigue and corrosion resistant [70]. These properties are exhibited by the various composites made by FSP. The combination of material can be sought out as per requirement. Composites can be designed to cater this need by changing the orientation of the fibers to improve mechanical properties [71]. Restricting fuel economy and improvement in safety as well as comfort is the demand in automobile industry. Light weight with durability, specific stiffness and high strength is required and is fulfilled by Aluminum metal matrix composites (AMMC's) [72]. High thermal conductivity of the composites along with chemical inertness, stability when irradiated, high mechanical resistance at elevated temperature etc. are a few features required for their active application of them in nuclear fusion and fission reactors. Most potential composite for nuclear application is Silicon Carbide reinforced Silicon Carbide (SiC-SiC) as it has all most all the required properties for fore-said application. Many biomedical devices and implants that use composites are in demand now. Man-made composites being close to the behavior of bones, tissues, skin, tendons etc. and with more advanced properties like strength, decomposition etc. have boosted restoration of some damaged parts [75]. HA/PEEK (hydroxyapatite and Polyether ether ketone) composite is fabricated using FSP, which has significant application in dental and orthopedics [76]. Use of pipes and risers in off shore oil 
and gas industries is well known, conventionally of steel work. Composites in this are require resistant to high temperatures, pressure, durability, fatigue resistance, high strength to weight ratio and sustainable against fluids like carbon dioxide etc. [77]. The MMC having reinforced with ceramic phases shows considerable improvement in properties such as high strength, better wear, fatigue and creep resistance and high elastic modulus making them fit for aerospace and automobile industries. For applications like electronic packaging material with lower thermal expansion coefficient are used. For such applications the thermal expansion coefficient can be decreased by reinforcing ceramic particles in the composite [78]. For applications like cutting tools, wear drilling inserts and rotor brakes, good wear resistance is required. Here $\mathrm{WC} / \mathrm{Co}$ and $\mathrm{SiCp} / \mathrm{Al}$ composites find their application [79]. Surface composites are providing superior properties which induces great functionality in the surface. One example of such application is a composite having high microwave absorptive material reinforced in the surface layer, this composite can be used for radar applications in stealth technology. FSP is a promising technique to tailor the surface properties like surface adhesion for a particular application such has to improve bio-compatibility [80].

\subsection{Future of FSP:}

Friction processing is an emerging technique in the world of material processing. It has an advantage over the conventional technique as it is a solid state processing technique. Several findings have been made ever since it was first used. Composites developed properties including grain structure, hardness, strength, ductility, corrosion resistance etc in contrast to the base material. Second phase materials including ceramics, fibers, metallic particles and nano tubes have successfully been reinforced using Friction Stir processing. Despite this success the technique still fails to prove be used at large scale as a more reliable process is required. Focusing on the current method of adding reinforcement phase lead to an uniform distribution therefore again failing the process for large scale fabrication of composites. Irrespective of having a non-consumable tool, there is wear to the tool observed which requires timely replacement adding up to the cost of the process. Further studies in this field emphasizing on industrial adaptation can pave way for commercialization of this great technology.

\subsection{Conclusion}

FSP is an adaptable surface composite fabrication technology. The distinctive advantages of this technique are the refinement of grains produced by FSP and the solid state aspect. Several surface composites generated via FSP have been found to include nano crystalline grains. The surface composites have a high degree of hardness, along with superior wear and corrosion resistance. FSP is a revolutionary approach for making surface nano composites that allows for easy particle dispersion. FSP has successfully introduced a variety of reinforcements into metallic matrix, including ceramic and metallic particles, as well as carbon nano tubes. It is possible to eliminate nano particle clumping. The FSP approach is advantageous in producing in-situ composites because it allows for no or very less of reaction products from the interface, which promotes additional reaction. Furthermore, the particles generated in situ are in the nano meter range. Hybrid composites with hard and soft reinforcements have been successfully created, and their properties are promising. FSP has employed a variety of approaches to ensure uniform dispersion of nanocomposites in order to fully exploit their potential. Studies have indicated that enhancement of the application and stability of coatings can be done by FSP. Promising results regarding FSP of polymeric composites are indicated by studies lately, however more research is needed.

Tool wear is a significant concern in the discussed process, specifically when working with materials like steel, titanium, or ceramic particle reinforced composites that have high melting point, this limits the application of the FSP in preparation of composites having hard surfaces.

\section{References}

1. Attia, A., Materials \& Design, 22(6), 451 (2001)

2. Rajak, D. K., Pagar, D. D., Menezes, P. L., \& Linul, E, Polymers, 11(10), 1667 (2019)

3. M., R., Gandra, J., \& Vila, P. Surface Modification by Friction Based Processes. Modern Surface Engineering Treatments. doi: 10.5772/55986 (2013)

4. Cole, J., \& Jue, J. Use of Friction Stir Welding and Friction Stir Processing for Advanced Nuclear Fuels and Materials Joining Applications. doi : https://inis.iaea.org/search/search.aspx?orig_q= RN:39009024 (2006)

5. Zagho, M., Hussein, E., \& Elzatahry, Polymers, 10(7), 739 (2018)

6. Neves Monteiro, S., Salgado de Assis, F., Ferreira, C., Tonini Simonassi, N., Pondé Weber, R., \& Souza Oliveira, M. et al. Fique Fabric: Polymers, 10(3), 246 (2018)

7. Zykova, A. P., Tarasov, S. Y., Chumaevskiy, A. V., \& Kolubaev, E. A., Metals, 10(6), 772. (2020)

8. Raja, A. R., Yusufzai, M. Z., \& Vashista, M, Proceedings of the ICAMM, 3, (2016)

9. Padhy, G. K., Wu, C. S., \& Gao, S, Journal of Materials Science \& Technology,34(1), 1. (2018)

10. Lv, J., Zheng, J. H., Yardley, V. A., Shi, Z., \& Lin, J, Metals, 10(11), 1516 (2020)

11. Sattari, B., Shamanian, M., Salimijazi, F., \& Salehi, M, Journal of Materials Engineering and Performance, 27(2), 751 (2018)

12. Tamadon, A., Pons, D. J., Sued, K., \& Clucas, D., Metals, 8(6), 375 (2018) 
13. Yang, Q., Xiao, B. L., Ma, Z. Y., \& Chen, R. S., Scripta Materialia, 65(4), 335 (2011)

14. Oh-Ishi, K., \& McNelley, T. R., Metallurgical and Materials transactions A, 36(6), 1575 (2005)

15. Navaser, M., \& Atapour, M., Journal of Materials Science \& Technology, 33(2), 155 (2017)

16. Khodabakhshi, F., Gerlich, A. P., \& Švec, P, Materials Science and Engineering: A, 698, 313 (2017)

17. Raja, S., bin Muhamad, M. R., Jamaludin, M. F., \& Yusof, F, Journal of Materials Research and Technology. (2020)

18. El-Shennawy, M., Abdel-Aziz, K., \& Omar, A. A., Int. J. Appl. Eng. Res, 12, 2832 (2017)

19. Zens, A., Gnedel, M., Zaeh, M. F., \& Haider, F.. IOP Conference Series: Materials Science and Engineering 373, 012018 (2018)

20. Pantelis, D., Tissandier, A., Manolatos, P., \& Ponthiaux, P, Materials science and technology, 11(3), 299 (1995)

21. Ratna Sunil, B, Materials Engineering, 11, 12 (2016)

22. Sharma, D. K., Jadav, H. H., Patel, N. P., Mahant, D., \& Upadhyay, G., Advances in Mechanical Infrastructure: Proceedings of ICRAM 2020, 133 (2021)

23. Sunil, B. R., Reddy, G. P. K., Patle, H., \& Dumpala, R., Journal of Magnesium and Alloys, 4(1), 52 (2016)

24. Gandra, J., Vigarinho, P., Pereira, D., Miranda, R. M., Velhinho, A., \& Vilaça, P., Materials \& Design, 52, 373 (2013)

25. Azizieh, M., Kokabi, A. H., \& Abachi, P., Materials \& Design, 32(4), 2034 (2011)

26. Hodder, K. J., Izadi, H., McDonald, A. G., \& Gerlich, A. P., Materials Science and Engineering: A, 556, 114 (2012)

27. Li, K., Liu, X., \& Zhao, Y., Coatings, 9(2), 129. (2019)

28. Patel, V., Li, W., Vairis, A., \& Badheka, V., Materials Sciences, 44(5), 378 (2019)

29. Ma, Z. Y. Friction stir processing technology: a review. Metallurgical and materials Transactions A, 39(3), 642 (2008)

30. Arokiasamy, S., \& Ronald, B. A., The International Journal of Advanced Manufacturing Technology, 93(1), 493 (2017)

31. Gangil, N., Siddiquee, A. N., \& Maheshwari, S., Journal of Alloys and Compounds, 715, 91 (2017)

32. M. Song, B. Huang, Mater. Sci. Eng. A 488 601, http://dx.doi.org/10.1016/j.msea.2008.03.022. (2008)

33. Gangil, N., Siddiquee, A. N., \& Maheshwari, S. Materials Today: Proceedings, 25,686 (2020)

34. Jalilvand, M. M., Mazaheri, Y., Heidarpour, A., \& Roknian, M., Surface and Coatings Technology, 360, 121 (2019)
35. Khodabakhshi, F., Simchi, A., Kokabi, A. H., \& Gerlich, A. P.. Materials Characterization, 108, 102 (2015)

36. Abbasi, M., Bagheri, B., Dadaei, M., Omidvar, H. R., \& Rezaei, M., The International Journal of Advanced Manufacturing Technology, 77(912), 2051 (2015)

37. Sunil, B. R., Kumar, T. S., Chakkingal, U., Nandakumar, V., \& Doble, M., Journal of Materials Science: Materials in Medicine, 25(4), 975 (2014)

38. Sharma, V., Prakash, U., \& Kumar, B. M., Journal of Materials Processing Technology, 224, 117 (2015)

39. Balasubramanian, V., Materials Science and Engineering: A, 480(1), 397 (2008)

40. Albakri, A. N., Aljoaba, S. Z., \& Khraisheh, M. K., In Advances in Sustainable Manufacturing (pp. 99-105). Springer, Berlin, Heidelberg. (2011)

41. Khayyamin, D., Mostafapour, A., \& Keshmiri, R., Materials Science and Engineering: A, 559, 217 (2013)

42. Zhang, Q., Xiao, B. L., Wang, W. G., \& Ma, Z. Y., Acta Materialia, 60(20), 7090 (2012)

43. Nia, A. A., \& Nourbakhsh, S. H., Transactions of the Indian Institute of Metals, 69(7), 1435 (2016)

44. Ramanjaneyulu, K., Reddy, G. M., \& Rao, A. V. Transactions of the Indian Institute of Metals, 67(5), 769 (2014)

45. Biswas, P., A Kumar, D., \& Mandal, N. R. Journal of Engineering Manufacture, 226(4), 641 (2012)

46. El-Sayed, M. M., Shash, A. Y., Abd-Rabou, M., \& ElSherbiny, Journal of Advanced Joining Processes, 3, 100059 (2021)

47. Mahmoud, E. R., Takahashi, M., Shibayanagi, T., \& Ikeuchi, K., Materials Transactions, 50(7), 1824 (2009)

48. Yu, Z., Zhang, W., Choo, H., \& Feng, Z. Metallurgical and Materials Transactions A, 43(2), 724 (2012)

49. Moustafa, E., Mohammed, S., Abdel-Wanis, S., Mahmoud, T., \& El-Kady, E. S., American Scientific Research Journal for Engineering, Technology and Sciences (ASRJETS), 22(1), 98 (2016)

50. Mirjavadi, S. S., Alipour, M., Hamouda, A. M. S., Matin, A., Kord, S., Afshari, B. M., \& Koppad, P. G., Journal of Alloys and Compounds, 726, 1262 (2017)

51. Qin, D., Shen, H., Shen, Z., Chen, H., \& Fu, L., Journal of Manufacturing Processes, 36, 22 (2018)

52. Santella, M. L., Engstrom, T., Storjohann, D., \& Pan, T. Y, Scripta materialia, 53(2), 201 (2005)

53. Satyanarayana, M. V., Adepu, K., \& Chauhan, K., Metals and Materials International, 1. (2020)

54. Barmouz, M., \& Givi, M. K. B, Applied Science and Manufacturing, 42(10) 1445 (2011) 
55. Zhang, P., Han, S., Ng, S., \& Wang, X. H. Fiberreinforced concrete with application in civil engineering. (2018)

56. Zeng, L., Liu, X., Chen, X., \& Soutis, C., Applied Composite Materials, 25(4), 843 (2018)

57. Morisada, Y., Fujii, H., Nagaoka, T., \& Fukusumi, Materials Science and Engineering:A, 433(1) 50 (2006)

58. Singarapu, U., Adepu, K., \& Arumalle, S. R. Journal of Magnesium and Alloys, 3(4), 335 (2015)

59. Fashami, H. A. A., Arab, N. B. M., Gollo, M. H., \& Nami, B, Journal of Advanced Materials, 4 (2015)

66. Mishra, R. S., Ma, Z. Y., \& Charit, Materials Science and Engineering: A, 341(1), 307 (2003)

67. Froes, F. H., Materials Science and Engineering: A, 184(2), 119 (1994)

68. Shesan, O. J., Stephen, A. C., Chioma, A. G., Neerish, R., \& Rotimi, S. E., Renewable and Sustainable Composites. IntechOpen. (2019)

69. Mavhungu, S. T., Akinlabi, E. T., Onitiri, M. A., \& Varachia, F. M., Procedia Manufacturing, 7, 178 (2017)

70. Snead, L. L., Nozawa, T., Ferraris, M., Katoh, Y., Shinavski, R., \& Sawan, M., Journal of Nuclear Materials, 417(1), 330 (2011)

71. Chen, F. M., \& Liu, X., Progress in polymer science, 53, 86 (2016)
60. El-Sayed, M. M., Shash, A. Y., Abd-Rabou, M., \& ElSherbiny, Journal of Advanced Joining Processes, 3, 100059 (2021)

61. Dialami, N., Cervera, M., \& Chiumenti, M. European Journal of Mechanics-A/Solids, 80, 103912 (2020)

62. Azizieh, M., Kokabi, A. H., \& Abachi, P, Materials \& Design, 32(4), 2034 (2011)

63. Kim, Y. G., Fujii, H., Tsumura, T., Komazaki, T., \& Nakata, K., Materials Science and Engineering: A, 415(1), 250 (2006)

64. Shamsipur, A., Kashani-Bozorg, S. F., \& ZareieHanzaki, A., International Journal of Modern Physics: Conference Series 5(5), 367 (2012)

65. Sharifitabar, M., Sarani, A., Khorshahian, S., \& Afarani, M. S., Materials \& Design, 32(8), 4164 (2011)

72. Almasi, D., Lau, W. J., Rasaee, S., Sharifi, R., \& Mozaffari, H. R., Progress in biomaterials, 9(1), 35 (2020)

73. Rajak, D. K., Pagar, D. D., Menezes, P. L., \& Linul, E. Polymers, 11(10), 1667 (2019)

74. Makarian, K., Santhanam, S., \& Wing, Z. N. Ceramics International, 42(15), 17659 (2016)

75. Huber, T., Degischer, H. P., Lefranc, G., \& Schmitt, T., Composites Science and Technology, 66(13), 2206 (2006)

76. Friedrich, K. Advanced Industrial and Engineering Polymer Research, 1(1), 3 (2018)

77. Delfini, A., Albano, M., Vricella, A., Santoni, F., Rubini, G., Pastore, R., \& Marchetti, M., Materials, 11(9), 1 (2018) 